\title{
The First Swede in Space: The Making of a Public Science Hero
}

\author{
By Andreas Gunnarsson
}

\begin{abstract}
The first Swede in space, Christer Fuglesang, has become an iconic figure for the popularisation of science in Sweden. Named as Sweden's first astronaut in 1992, Fuglesang remained a relatively anonymous and somewhat derisory figure prior to his space launch in 2006. After his space mission, however, Fuglesang has become the very personification of science in Swedish society. In this paper, the transformation of Fuglesang's public persona and his construction as a Swedish public science hero is analysed in detail. It is discussed how after 2006, Fuglesang can be seen as providing confirmation, both of the existence of a cultural gap separating science from society, and of the ability of certain heroic individuals to bridge this gap in a way that renders it more appreciable to a larger public.

In the main part of the paper, three aspects of Fuglesang's elevation into a Swedish public science hero are discussed: First, the cyborg metaphor is used to analyse the fearlessness Fuglesang expresses towards yielding to, and entering into close communion with science and technology. Second, the transcendence of earthly perspective aspired to by science for so long, and apparently realized through space travel, is discussed in relation to Fuglesang's personal experiences of space. Third, the inseparability of Fuglesang's nationality from his heroism is discussed. It was only through the repeated flagging of his Swedishness that Fuglesang's routine space mission gained any particular significance enabling it to be communicated as a major scientific event.

Finally, closer attention is paid to the scientific message Fuglesang is delivering to Swedish society. It is argued that he acts to promote renewed faith and confidence in the ability of science to open up new horizons for the future. The task of the public science hero is to help enable these new horizons to colonize the public imagination.
\end{abstract}

Keywords: Christer Fuglesang, cyborg, popularisation, science hero, space travel, Sweden 


\section{Introduction: An Occasion to Look Up to Science}

On January $25^{\text {th }}$ 2007, Christer Fuglesang - the first Swede in space - was treated as a returning hero as he was welcomed back in Stockholm. Included in his reception committee was the Swedish Minister for Education, Lars Leijonborg who greeted him by saying: "You are a living hero who has proved that even a doctor of particle physics can be an idol”(Aftonbladet 2007 Jan. $27^{\text {th }}$ ). Fuglesang's space mission (official name STS 116/ISS 12A.1) had taken off from Cape Canaveral on $9^{\text {th }}$ December 2006. As with most shuttle missions to the International Space Station (ISS), this one had included construction work on the space station and a change of crew members. Four space walks took place during the mission and Fuglesang participated in three, before the shuttle Discovery returned safely to Earth on $22^{\text {nd }}$ December.

In the year that followed Fuglesang's space flight, he was rarely out of the public eye in Sweden. He received numerous awards; published two richly illustrated books on his life; participated in countless radio and TV shows; inaugurated the country's largest science festival; campaigned in the press for more funds to space research, and had an asteroid named after him in connection with a visit to Uppsala University. How are we to make sense of the carousel of highly celebratory forms of public science set in motion in Sweden by what must now be seen as a routine incidence of manned spaceflight 45 years after Gagarin? The aim of this paper is to analyse how space travel has succeeded in transforming Fuglesang into both a symbol for the unquestionable authority of science in Swedish society, and a public hero capable of re-asserting a vision of the centrality of science to the continuing advance and well-being of the Swedish nation as a whole.

Although the problematization of science and society relations in terms of a deplorable deficit, or absence, of public understanding and appreciation of science has been profoundly questioned in recent years, its grip on science communication and popularization practice remains strong. ${ }^{1}$ The need to award science and scientists a higher level of public respect and admiration than is typically on offer, will be discussed in this paper as clearly underlying the heroizing of Christer Fuglesang in Swedish society since the beginning of 2007. As Felt (2000) has pointed out, popularisation can be fruitfully analysed in terms of its functional capacity. Internationally, science communication and popularisation have tended to be treated as solutions to various problems and perceived threats to the reigning institutions of science:

It was important to educate an entire society to be ready to support science and invest funds. In countries where the science system was in financial straits [...] it was important to remind the public regularly of the general impact that science had on the development of society. (Felt 2000: 30) 
In public discourse, the underlying problem is typically depicted in terms of lost opportunities and retarded progress. The general interest for science and technology, and for education in these areas are regularly said to be lapsing throughout "the Western World", at the same time as unreasonable fears and doubts about the benefits of science and technology are apparently growing. Under these circumstances, pre-eminence in science and technology and the societal advantages this infers are portrayed as on the verge of slipping from the nation's grasp. ${ }^{2}$ By avoiding any ambivalence about the expanding science-base of contemporary society, conventional forms of popularisation have persistently addressed problems concerning the public uptake of, and appreciation of, science and the uncertain ability of communication practices to ameliorate these (Wynne 1995: 370, 38488).

As will be discussed in this paper, Christer Fuglesang has come to personify an alleged gap between Swedish scientific achievement and the rest of Swedish society, at the same time as he is seen as currently symbolizing the best available means for spanning this gap, and making genuine scientific achievement tangible and palpable to the Swedish citizenry at large. The idea of a deep rift dividing science and society that only a few like Fuglesang can successfully bridge has been conceptualised by Bensaude-Vincent (2001) as the foundation of a hierarchical relationship between science and the public. The existence of a gap, or distance, between scientific and lay knowledge has tended to be central to the understanding that Western science has held of itself. Since the middle of the nineteenth century the popularization of science has strived to create a mass audience for scientific knowledge presented as indispensable to society while still always tantalisingly beyond its reach. This conception of the science-public relation has formed the basis for the growth of various public intermediaries and popularisation specialists thought of as public ambassadors and envoys of science, or even scientific missionaries. Through their communicative efforts these individuals have all helped to cement the idea of an inescapable gap between science and society at the same time as they have continually presented themselves as commanding the means to ameliorate it (Bensaude-Vincent 2001). The gap-bridging activities of science popularizers supports a linear communication model that views popularization as a process of translating ready-made science into simplified knowledge packages fit for general public consumption (Hilgartner 1990). This approach can then be seen as structuring a complete range of settings where science orientates itself towards outside audiences. The manner in which the established institutions of science seek to maintain legitimacy, epistemic priority and autonomy, as well as public support and appreciation - has been famously described by Gieryn (1983) as boundary work. Not to be viewed as cynical manipulation, Gieryn argues that boundary work is a vital part of professional development and works to enable scientists to maintain expert authority and public sup- 
port by negotiating the boundaries between science and non-science. Consequently, science becomes a central, yet external authority in society, as popularisation and science communication are presented as dedicated to bringing higher asocial knowledge down to Earth. The value of Fuglesang as a populariser is to be found in his role as a definitive "gap-man" - someone so clearly set apart from the population at large, yet so spectacularly able to bring scientific achievement into public view.

\section{Christer Fuglesang 1992-2006: Not Quite the "Right Stuff”?}

The heroic status of Christer Fuglesang which was repeatedly recognized and confirmed in Sweden during 2007, remained undecided until the moment of his launch into space in December 2006 projecting him out of relative anonymity. Prior to launch, his public profile was low rather than high, and anything but unambiguously celebratory. For this reason, a short background concerning the development of Fuglesang's public image is appropriate in order to more clearly depict his transformation into a true science hero.

In 1992 Christer Fuglesang was announced as the first Swedish astronaut and one of six ESA (European Space Agency) astronaut candidates (Fuglesang 2007: 59-60; Dagens Nyheter 1992 May $16^{\text {th }}$ ). His first potential space mission was to the Russian space station Mir on the second of two flights that the ESA had negotiated called EuroMir94 and 95. Fuglesang and the German astronaut Thomas Reiter were selected to train for the second flight, but when the final decision was made, Reiter was favoured over Fuglesang who was named as the backup astronaut. Fuglesang has described this as a frustratingly political decision, and a great personal disappointment made worse by erroneous Swedish newspaper reports stating that he had been the one chosen for the flight (Fuglesang 2007: 98-99, 147, 158-160; Expressen 1995 Mar. 17 ${ }^{\text {th }}$; Svenska Dagbladet 2002 Feb. 28 ${ }^{\text {th }}$; Expressen 2003 Mar. $30^{\text {th }}$ ).

In 1996, a Swedish TV comedy show called Percy tårar, with the popular comedy team Killinggänget, made satirical comment on Fuglesang's prospects of becoming the first Swede in space. Using Fuglesang's real name a series of sketches presented an astronaut joining the Swedish space programme hoping to become a member of the first Swedish mission to the moon. First, Fuglesang and the other candidates for the mission undergo a series of hilarious tests and exams in order to ascertain who shall board the X-9 rocket. But then the competition gets much tougher as two German candidates arrive. Unable to compete with the superior skills of the two Germans, and as the third place on the mission is assigned to the programme director's favourite student, Christer is sadly left earthbound surrendering to drugs as the only way to contain his sorrows (SVT 1996). Apparently making fun of his competition with Reiter, and the futility of his long and arduous 
training, the real Fuglesang later publicly announced that he found it strange that his actual name had been used in the sketch, jokingly adding, that by rights he felt he should have been paid for the liberty taken (Expressen 2003 Mar. 30 ${ }^{\text {th }}$ ).

Following Reiter's EuroMir95 mission, Fuglesang transferred to NASA in Houston in 1996 to undergo further astronaut training. At NASA, he joined a large group of astronauts and was again passed over several times in the planning of space missions, before in 2002 being designated a "mission specialist" on the planned launch STS116/ISS 12A.1 scheduled for May 2003 (Fuglesang 2007:18991, 199-202). However, on February $1^{\text {st }} 2003$, just months before the scheduled flight, the space shuttle Columbia blew up on re-entry and all aboard were killed. Fuglesang's mission was immediately postponed. Therefore, when he finally lifted off on December $9^{\text {th }} 2006$, fourteen years had elapsed since he was publicly named as the first Swedish astronaut.

As this brief history suggests Fuglesang's early appearances as a public figure were associated with a combination of excitement and expectation repeatedly followed by reports of disappointment and frustration as "the first Swede in space" remained stuck on the launch pad once again. The 1996 satire of him as a naïve dreamer, and a victim of circumstance, outcompeted by the stellar performances of the German astronauts, played on his real life frustrations. In the satire Fuglesang is depicted as not quite the "Right Stuff" and as a figure of public derision. Therefore prior to launch, Fuglesang resembled more a public picture of inadequacy connected with broken dreams, not an untarnished hero in the making. Even though some of the features of the pre-flight image have resurfaced now and again in the post-flight era, the past has largely been forgotten and erased in media representations of Fuglesang after 2006. Fourteen years standing in line for a launch have been re-interpreted and praised as signifying great tenacity and perseverance.

\section{The Post Flight Persona - How and Why Fuglesang Became a Functional Figure for the Popularization of Science in Sweden}

The public persona of Fuglesang after 2006 is that of a paragon of personal and professional achievement. There are, however, several distinct sides to this heroic image which shall be subject to separate analysis in the following sections of this paper. The different sides of Fuglesang's projected heroism relate to the different ways in which he can be seen as wedded to science and technology. Each of these ways enables him to emerge as a genuinely outstanding and exemplary individual commanding skills and experience that many can aspire to gain, but only a few can actually obtain. Together the different sides of Fuglesang's heroic persona serve to manufacture him as a symbol for both the gap dividing science and society, and the respect and admiration rightly sought by the former from the latter. 
The three sides to Fuglesang's heroic self will be discussed under the headings: cyborg relations; space experience and perspective; and hard working Swedish hero. These three themes are meant to show how the space mission served to remove the ambiguities of the pre-flight identity and position Fuglesang as a role model fit to both confirm and reinstate the great science-public divide.

\section{Cyborg Relations - The Ability to Live with Technology}

Shortly after the STS 116 mission, the National Museum of Science and Technology in Stockholm opened their exhibition "An Adventure in Space”. Hanging from the ceiling above the displays was a mannequin representing Fuglesang in

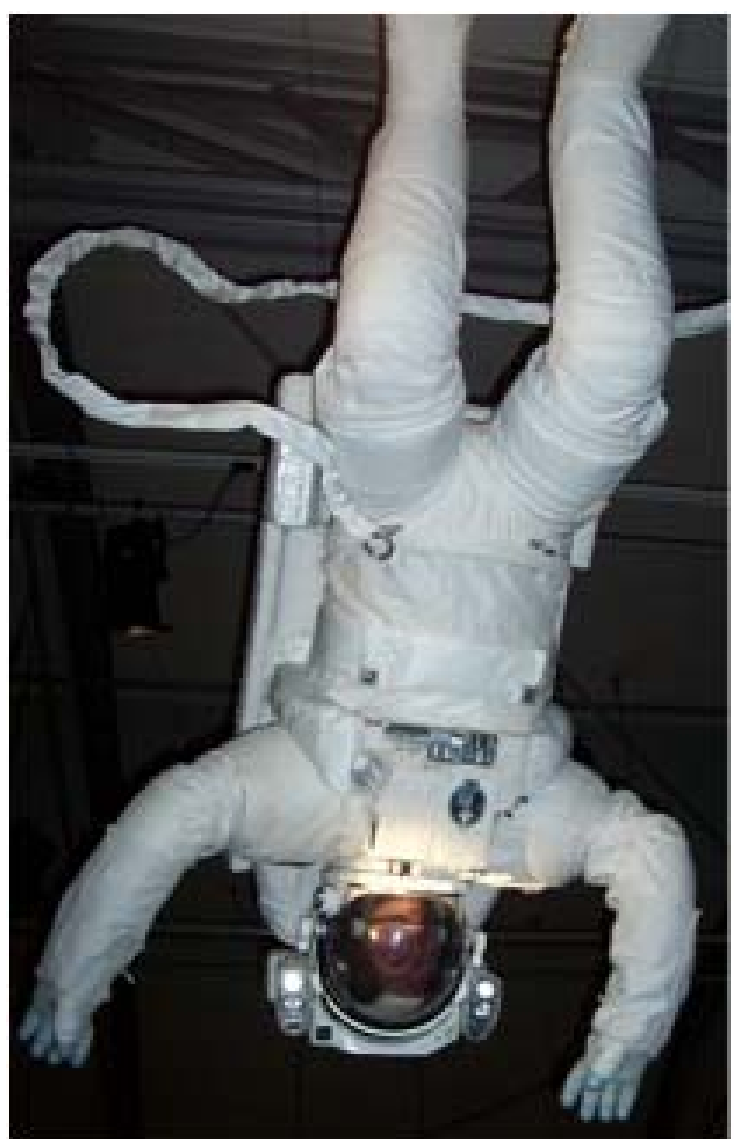

Figure 1. Mannequin from the exhibition "An Adventure in Space” in Stockholm.

Photo: Andreas Gunnarsson. his space suit. This mannequin will here be taken as a starting point for a discussion of how Fuglesang's achievement is broadly advertised as built upon his exemplary marriage to science and technology. As Benita Shaw (2004) has argued, the space suit itself is simultaneously the uniform worn by the heroic conqueror of space and a sign of otherworldliness. The visor of the space suit depersonalizes the astronaut rendering him indistinguishable from his fellows and closely resembling the heavily armoured knight of old - a former figure of depersonalized valour and virtue. Although the mannequin in the space suit at the Stockholm exhibition could not be mistaken for anybody else than Fuglesang, he is still displayed as a detached, anonymous figure, encapsulated in technology, secured to a space station with a lifeline resembling an umbilical cord (Shaw 2004). As Fuglesang himself has testified, the practice of spacewalking, or EVA (Extra Vehicular Activities), requires careful preparations: "the batteries and the pressurization of the suits were continually monitored, the cooling tested, the oxygen level closely controlled. Nothing is left to chance. To go into space, into a vacuum, is not like taking a walk in the park.” 
(Fuglesang 2007: 110). Getting into the space suit itself took almost an hour, and the whole process of preparing a spacewalk took several hours. Again as Fuglesang confirms: "You cannot be claustrophobic if you want to get into a space suit" (Fuglesang 2007: 109). But even though it is a cumbersome and confining environment its purpose is to make purposeful action in space possible. This state of voluntary subjection to technical imperatives which are understood as both confining and enabling is a prominent theme in the construction of Fuglesang's heroic post-flight persona.

Part of the extraordinariness of the astronaut relates to his ability to enter into complete unison with the technologies required for space travel. The emphasis on physical and mental training and testing procedures in many astronaut narratives (e.g. Wolfe 1979; Fuglesang 2007) can be viewed as relating to the necessity of finding and fostering individuals compatible with the technologies of space flight. The astronaut must not black out under high g-forces; must be able to cope with weightlessness and able to keep his heart rate down under pressure. The body of the astronaut is a monitored body - monitored in space, but also closely surveilled on Earth. In Fuglesang's case, the process of getting clearance to participate in a space mission translates into a story of accommodating and complying with a vast array of medical test procedures. With his initial move from the ESA in Germany to Star City, Russia, Fuglesang recalls being subjected to two weeks of intensive medical tests and physical examinations: "It obviously wasn't enough with everything that the ESA had already subjected us to: the Russian doctors wanted to have a look themselves and also do additional tests. Gastroscopy was one of the less pleasant [...]” (Fuglesang 2007: 100).

And again as he transferred from Star City to Houston:

[...] first I had to go through NASA's medical examination. Doctors in different countries can't have a lot of trust in each other. I had already been examined by Swedish, European and Russian doctors more than a normal human is in a lifetime, but still this didn't do. (Fuglesang 2007: 170)

The cyborg has become a much discussed figure, as a science fiction character, as a hybrid subjectivity, and as an actual technological possibility. The term originates from the article "Cyborgs and Space" by M. Clynes and N. Kline (1960/1995), where they pose the question of how a fish that wished to live on land would go about doing that - would it bear with it a small amount of water, or would it be better to modify itself technologically? This metaphor for man in space makes the point that dragging your natural environment around with you is both cumbersome and risky, as it will always remain fragile and vulnerable. Instead man should, like "a particularly intelligent and resourceful fish" seek to incorporate technical devices, thereby "creating self-regulating man-machine systems". Freeing humans from maintaining complicated life-sustaining systems this would "leav[e] man free to explore, to create, to think, and to feel". (Clynes \& Kline 1960/1995: 29-33) Since Clynes and Kline’s article, the figure of the cyborg 
has taken on an expanded meaning, often being viewed as a metaphor for humanmachine systems in general. The astronaut cyborg differs from the intelligent fish imagined by Clynes and Kline in that the astronaut is encapsulated in technology rather than the other way around (Shaw 2004). Treating the body of the astronaut as contiguous with technology and as something to be automatically monitored and controlled, promises to liberate human powers of mind and vision enabling them to be dedicated to higher purpose (Romanyshyn 1992: 114-17). The astronaut frees himself from his bodily limitations by subjecting his body to the technological systems that sustain it (Bryld \& Lykke 2000: 30-31, 113-15).

Depicting parallel conceptions, Gerovitch (2007) relates how the image of the cosmonaut was linked to the idea of "the new Soviet man", bringing together the human and technological qualities required to form a simultaneously rationalistic, efficient and creative individual. Even though the spaceships were almost completely automated; "Soviet propaganda vividly portrayed cosmonaut heroes bravely flying their spacecraft into the unknown" (2007:136). The cosmonaut was expected to remain calm at all times, to be able to continuously monitor and report on various instrument readings, and to be capable of following orders and procedures even under circumstances of extreme duress. These expectations applied regardless of whether the cosmonaut was on a space mission, still completing his training, or performing public duties. The expectations placed upon the US astronaut turn out to be very similar (Gerovitch 2007).

Tom Wolfe's The Right Stuff (1979) depicts how the nature of heroism changed with the emergence of the astronaut. The contradiction of being both further enabled by, and enslaved under technology is explicitly described by Wolfe when he tells of the meticulous testing procedures candidate astronauts were subjected to, and their levels of opposition/acquiescence with regards to the (very low) levels of control they were granted over the Mercury capsule. This kinship of the cosmo/astronaut - that Gerovitch identifies in terms of "a split self: both a distinct individual and a little cog, a master of technology and a part of the machine” (Gerovitch 2007: 155) - is what makes him such a good public representative of science and technology - a master and slave rolled into one.

This is particularly evident in the negotiations surrounding extensive and sometimes humiliating medical testing. In order to be selected and approved for space travel the astronaut must undergo the tests, but in order to remain a distinct and heroic, masculine individual he must do so under reasonable protest. Protesting too much, or opposing the tests outright would mean a failure to live up to the demands placed upon astronauts. This is the explanation both Wolfe and Launius provide in their texts for why Peter Conrad did not become one of the Mercury Seven crew. According to them both, Conrad was simply unwilling to submit to the medical and psychological testing, mocking and ridiculing the testing procedures (Launius 2005; Wolfe 1979). 
Fuglesang's depiction of the testing procedures he was subjected to decades after the initial problems experienced trying to turn maverick fighter pilots into astronauts, speaks of a much more accommodative attitude: a measure of jocularity without actual opposition:

\begin{abstract}
Worst was the so-called vestibular training, which consisted of developing ones resistance to motion sickness by sitting in spinning devices. The idea is that it should help against space sickness as well, but I'm not convinced. Every other day we went to what we jokingly called the torture chamber and were spun until we became nauseous. [---] I noted an interesting Pavlov's reflex in myself: after a while my hands got cold and sweaty already in the hallway on the way to the spinning device. (Fuglesang 2007: 97)
\end{abstract}

Public interest in astronauts tended to decline after the end of the 1960s, while space launches and landings continued to remain popular spectacles. David Nye (1994) has described this not only in terms of "the machine's displacing the hero", no longer viewed as particularly exceptional, but also as reflecting the sublime qualities of the launch itself. The awe-inspiring spectacle of the launch has not lost its powers of attraction as an example of what Nye calls the American technological sublime. Linked by many viewers to feelings of patriotism and feelings of American technological superiority the launch serves as both as an object of spectacle and display (Nye 1994: 238-56). Even if the feelings of national pride are no longer as closely tied to the astronauts so much as to the spacecraft they inhabit, the former are still seen as showing an appropriate relationship to science and technology. On top of the rocket, the astronaut so to speak leads by example, when he fearlessly blasts off into space; demonstrating that technology should be consumed and surrendered to, rather than resisted and always treated with fear and caution. This masculine heroism of the astronaut is formed, not in opposition to the technologies of space flight, but in successful combination with them. Mixing metaphors, the fearless white-suited space knight blasting into the unknown fits well with what Constance Penley has called "the WASP space cowboy version of spaceflight" (1997: 58) that while remaining so celebrated excludes other visions of space travel. Despite widespread public ambivalence towards the unfettered inventiveness of science, the astronaut is still being mobilized to demonstrate that faith and confidence in science and technology pays off, both for the individuals concerned and the communities they belong to. As Fuglesang himself has expressed it: "Humanity would not have gotten far if it hadn't exposed itself to risks" (Expressen 2003 Mar. 30 ${ }^{\text {th }}$ ).

The potential risks of the launch situation have been brought to the fore not least by the launch-related accidents of Challenger in 1986 and Columbia in 2003. According to Nye, the Challenger disaster led to even bigger crowds at launches, since it "dramatized the danger of the launches and rescued them from the banality of uninterrupted success. It fulfilled the dark promise of unimaginable violence 
that had always been an unconscious part of the experience of witnessing a launch.” (Nye 1994: 251-52).

After much publicized accidents, to sit on top of the rocket in front of thousands of people, waiting for take off takes on the character of a public showdown between those who are still able to subscribe to an unalloyed faith in scientific and technological progress and those who preach greater caution. Under these circumstances, the astronaut is the embodiment of continued and renewed faith in science and technology, someone still determined to compete to put their life and soul on the line, confident that their vital signs will not betray them. Fuglesang plays out this role of confident believer when he is surprised by his own cool. Describing his feelings on a dictaphone four minutes from lift-off he notes: "Still really not that jittery; more the wonderful feeling of expectation, definitely no nervousness.” (Fuglesang 2007:13; Sveriges Radio 2007) This is how the tension of the launch is expressed: exciting and wonderful, but not scary or nerve-racking. What is about to happen is not tainted by any dark fears or doubts, but filled with promises and expectations - and it is recorded in a calm and collected manner, as a memento of the launch as equivalent to a moment of technological re-birth.

\section{Space Experience and Perspective}

Having cultivated an appropriate relation to the technologies of space travel the astronaut is finally launched into space. The journey into space itself is an unconditional requirement if the astronaut is to become a functional hero for the popularization of science in society. Being literally out of this world, space travel appears to deliver on a transcendental promise made by science to society. But why space travel should continue to be seen as so astounding today begs explanation not least as the "god's eye view" awarded to the astronaut has grown so commonplace as images of Earth from space have permeated everyday life (Cosgrove 2001). In this context Fuglesang is inclined to downplay the novelty and impact of the view from space, without devaluing the opportunity to witness it firsthand:

Some of the most frequent questions I've been asked since I returned from space concerns how it affected me as a person. Have I changed? Is my outlook on life different after I've seen the Earth from above, from a view that has been granted so very few? [...] I'm pretty sure that I haven't changed from my time in space [...] None of my crew colleagues claims to have changed to any appreciable extent and none of us are surprised about that. We knew fairly well what we would experience, even though there is a great difference between seeing pictures of it and seeing it with your own eyes. (Fuglesang 2007: 334)

When astronauts leave Earth they evoke an entire field of meanings and promises connected with the transcendence of Earthly perspective and something that has been a central component of both the scientific and broader cultural imagination at least since Copernicus and Galileo (Romanyshyn 1992: 42). The perspective from 
space is privileged because it combines a detached ideal of knowledge with a practice of witnessing central to modern science and technology.

Hannah Arendt (1958) describes science as a quest for achieving "the Archimedean point" which is repeatedly afflicted with "Cartesian doubt". That is, science is a quest for an all-seeing point of observation which perennially falls victim to the belief that all sensory perception is false and illusionary. Science lives with both conceptions and attempts to resolves the contradiction by placing the Archimedean point within the mind, so as to make the point a concept or ideal rather than an actual location:

Without actually standing where Archimedes wished to stand [...], still bound to the Earth through the human condition, we have found a way to act on the Earth and within terrestrial nature as though we dispose of it from outside, from the Archimedean point. (Arendt 1958: 262)

The cultural significance of actually viewing the Earth from the outside should not therefore be underestimated. As Cosgrove points out, using Apollo as his metaphor for the transcendent perspective, although images of the globe play an important part in western history and culture, still very few people have actually seen the Earth from the outside:

Achieving the Apollonian perspective, so long anticipated in imagination, produced an unconscious but perhaps predictable set of responses - marvel at a vast yet tiny Earth, reflection on the insignificance of self, and yearning for human unity. [---] Humans were henceforth neither grand actors at creation's centre stage nor helpless creatures at its margins. (Cosgrove 2001: 258-59)

The awe-inspiring transcendence of Earth and the view from the outside is clearly articulated by Fuglesang in his published books, for example when he describes his first space walk:
At the same time the day dawns and the Earth reveals itself beneath me. It passes by at high speed. Sea and clouds. [---] I see a much wider view than from inside through the windows. It is very, very beautiful and I can hardly believe that I am here. (Fuglesang 2007: 116)

Fuglesang describes not only the marvel of a transcendent perspective - be it Archimedean or Apollonian - but also the act of witnessing that goes with it positioning him apart from the rest of society.

Witnessing from space has much in common with scientific witnessing practices (Shapin \& Schaffer 1985; Haraway 1997), not least since it both realizes the ideal of detached vision and is subject to advanced technical mediation. The marvel expressed above corresponds with, and confirms the privileged vantage point that has been won. Both Western culture in general, and Western science in particular, are heavily indebted to witnessing from privileged points through the technique of linear perspective. With the prominence of linearity in occidental culture what is viewed becomes deeply dependent on the position of the viewer. The procedures of the linear perspective, argues Romanyshyn: 
have been taken up, elaborated, and amplified to allow the development of a technical world. [...] we have played out in plural fashion the role of being an onlooker on this side of the window observing a world which in myriad forms has become something to be observed. (1992: 57)

With linear perspective, vision and visual representation are central to the perception of the world, and vision is dependent on positioning. The Copernican replacement of the Earth as an object among other objects makes possible our release, and ultimately our escape, from it (Romanyshyn 1992: 35-58,147-48). If the Earth were not an object that could be observed, it would not be possible to transcend it. This is part of the explanation for why astronauts can claim a privileged status as scientific witnesses: through the separation of the object and subject of knowledge, the view from space has been anticipated for centuries, and the astronaut is cast as the one who finally realises it. A difference in experience and perspective opens up between the astronaut and those left on Earth, similar to the expert - lay divide represented by Bensaude-Vincent's gap. A decisive difference in experience and perspective gives the astronaut not only the right, but also the obligation to communicate and share this unearthly vision and experience. Fuglesang does this in many forms, perhaps most notably in his books about space and his mission (Fuglesang \& Tell 2007; Fuglesang 2007).

The astronaut becomes both our representative in space and a representative for the space experience and perspective - the astronaut bears witness for all of us not in a position to see what he sees. To be a witness is to be a mediator, who we can or cannot treat as credible (Peters 2001). Shapin and Schaffer (1985) show how the act of displaying and witnessing became crucial to the birth of experimental science and the establishment of matters of fact. By staging his experiments for an audience of reliable and respectable "gentlemen" Boyle was able to establish experiment as a valid path to knowledge and the unveiling of nature. Gentleman witnesses were suitable for this task not because they represented the view of anyone, but because they represented the view of someone - someone eminently trustworthy and respected. For Boyle these witnesses were suitable because they were also formally detached from the experiments they witnessed (Shapin \& Schaffer 1985). However, the astronaut is not such an independent witness as the gentlemen of old. Instead he has grown indistinguishable from the science he is tasked with warranting and authorizing. Haraway's figure of the Modest Witness signals how the characteristics of the witness are positioned in order to transform their testimony into the solid foundations for the construction of facts. Haraway's work insists that the ideal of objective witnessing is by no means detached from perspective and interest. The modesty of the witness depends upon the denial of their situatedness. By claiming universality for their testimony scientific witnesses become themselves universal entities, unmarked and transparent figures, (Haraway 1991: 183-96; 1997). ${ }^{3}$ This is one of the reasons why the astronaut becomes such an important symbol for science and technology: Fuglesang has achieved a 
vantage point which transforms him into a privileged witness; simultaneously one of us and not one of us. Thereby his accounts of how the Earth appears from space can be accepted as valid and true, we can trust him in the same way we can trust the science and technology that have elevated him into the position from which he views the world.

\title{
Hard Working Swedish Hero - Bringing the Astronaut to the Public
}

\author{
I was honestly more nervous then [landing at the airport in Stockholm] than I was \\ lying strapped down in the space shuttle on the launch pad. Then I knew fairly well \\ what to expect. Now all I had understood was that the interest was large [...]. The \\ welcome and reception were truly magnificent. (Fuglesang 2007: 331)
}

The deficit model understands the science-public relation as a difference between the scientist who is in possession of privileged knowledge and "the public" made up of lay people who have yet to be made a party to this knowledge (BensaudeVincent 2001). The role of popularisation thus becomes to repack and translate science into a form that is sufficiently palatable and comprehensible to lay audiences (Hilgartner 1990: 519-20). Therefore, while popular science is meant to be diluted science, maintaining science's preferential right of interpretation, it also tries to appeal to lay audiences by relating to what they are imagined to be already familiar with. This suggests the introduction of science into everyday life in a particular way, as attempts are made to wed science with the mundane. Myers sums up the problem when remarking that popularisation is a field "defined in terms of what it is not. [---] Popularisation includes only texts about science that are not addressed to other specialist scientists" (Myers 2003: 265). It is this "down to Earth" meeting with the public that makes Fuglesang nervous in the above quote; now that space mission is over, the public mission still remains. In the texts meant to frame, explain and report on Fuglesang's mission, the combination of elements of otherworldliness and mundanity are played out in a variety of ways, often oscillating between celebrations of the heroic astronaut and devices meant to root him and the science and technology he represents in the realm of the popular. Finding the balance between celebrating the unique qualities of Fuglesang's achievement while developing further a sense of identity between him and his audience remains a constant challenge.

All spacesuits come with flags attached, in Fuglesang's case it is a Swedish flag and, as was noted in the media coverage, recruiting representatives from different nations seems to have become a way for NASA and the Russian space program to broaden and maintain their public appeal (Östersundsposten/TT Spektra 2006 Dec. $\left.7^{\text {th }}\right)$. At the very core of the public interest in the STS 116 mission and in the celebrations of Fuglesang is his nationality. To claim that a space mission could be ordinary or mundane might seem ridiculous, but as far as the history of space flight is concerned, the STS 116 mission bore no resemblance to the groundbreaking missions of the early 1960s. In keeping with the space race analogy one might 
say that all the medals were won a long time ago. Therefore, the scale of Fuglesang's achievement is completely dependent upon which public is being asked to recognize it. For any other than a Swedish public, Fuglesang's exceptionality is difficult to register. Therefore, his ability to serve as a prominent ambassador for science and technology in society is severely delimited and fully-dependent on his ability to endlessly and tirelessly wave the Swedish flag.

When passing the TV-cameras on the second launch attempt, Fuglesang held up a sign with the text "HEJA SVERIGE, Heja Norge. VIVE L'EUROPE” as a display of his public commitments. First to Sweden, in capital letters, then Norway, in small letters and as a greeting to his Norwegian relatives, and finally to Europe, to the ESA and his French friends on the site. But the Vive L'Europe is also because:

I think we need to cooperate more and
better in Europe in order to create a manned
space program equivalent to the USA's and
Russia's. In addition we should spread our
values in the world - and in the future into
space. (Fuglesang 2007:12)

The symbols are present all through the launch process; one does not go into space merely as an individual, but also as a patriot. On Fuglesang's spacesuit the Swedish flag figures in two ways, as the plain flag that all astronauts carry on their shoulder, and as part of the mission badge for STS 116 together with the stars and stripes. Apart from the obvious symbolism of the space shuttle being carried into space from the USA by the two flags, this image gives Fuglesang's nationality great prominence. The badge design signals that NASA takes the Swedishness of Fuglesang very seriously. And his nationality was often underlined, before, during and after the mission. For example, other crew members asked him to talk Swedish when they were filming him or to say something typically Swedish, mission control also played an ABBA song as the wake up tune one morning, and the foods Fuglesang brought with him included elk sausage. (Fuglesang 2007; Sveriges Radio 2007).

All of these markers, served to remind us of and to anchor Fuglesang in a Swedish context made up of everyday cultural fragments such as food, music and phrases. Most of them are very well known, some even emblematic for Sweden, 
like the elk that is used in numerous advertising campaigns, or ABBA - one of the country's most successful music exports. Others are more personal like the phrase "Fina fisken", a somewhat outdated expression meaning that all is ok. The use of national markers has served to connect Fuglesang to Sweden, his accomplishments thereby become Swedish ones. Establishing a common denominator between him and, for example, the children envisaged as becoming interested in science and technology strengthens his role as an example for others.In this sense the appeal to national symbols upholds a connection that otherwise could easily be questioned. Like many other successful individuals with scientific and/or technological careers, Fuglesang has made his career on an international rather than a national stage. Leaving Sweden as early as 1988 to work at CERN and live in France, he went on to Germany, Russia and the United States (Fuglesang 2007: 36). Fuglesang has arguably run the risk of losing touch with many of the cultural markers of everyday life that make up an important component in the construction of banal nationalism. On the other hand, banal nationalism is in many ways an essentialist ideology: nationality is imagined to be determined by birth or upbringing and incorporated as a fixed identity (Billig 1995: 61).

This national identity then forms the basis for the international relations between nations and between the citizens of different nations. Internationalism should therefore be regarded not as an alternative to nationalism, but rather as a feature of it (Billig 1995: 80). Fuglesang's Swedishness is played out in a similar fashion both by himself, and by others - from the official representatives of the nation to the flag-waving crowds, all recognize that Fuglesang's achievements are to some degree national achievements. This could be explained as just a "natural" relation between a nation state and one of its citizens, but that would be to overlook the interdependence of astronaut and nation in the way that they are implicated in strengthening images and representations of each other.

Even though the return of Fuglesang to Sweden might be accurately described as a moment of "hot" nationalism, with flags being waved and a meeting with the King, I would argue that the contextualisation of Fuglesang and the mission as a Swedish event is more a result of unreflective banal nationalism. Billig (1995) distinguishes two forms of nationalism: the "hot" one usually reserved for separatist movements; and the banal, everyday nationalism signified by constant flagging and flag-waving, serving as a reminder and a reiteration of community membership. Banal nationalism forms the basis for outbursts of hot nationalism, like the patriotic flag-waving crowds at American rocket launches described by Nye (1994). For Fuglesang's space mission to gain recognition as a major technological event, it must be simultaneously encoded as a national event. Fuglesang is not first in space in any popularly significant way other then being the first Swedish passport holder to orbit the Earth. The displays of Sweden and Swedishness are present on all levels, making it simultaneously significant and natural. By ground- 
ing the representation in a banal nationalism Fuglesang's public image can draw on existing symbols and markers - flags, foods, language and so on - to successfully attach the astronaut both to a Swedish public and an international space program.

In connection with the launch Fuglesang made a statement to the press about his long wait for a mission in which he claimed that the Swedish government had not been supportive enough. Other countries had paid to get ahead of him (Hallands Nyheter/TT 2006 Nov. 21 ${ }^{\text {st }}$ ). His argument did not express personal disappointment so much as a sense national betrayal. He did not say that other individuals had bought their way into space before him, but that other nations had strived harder than Sweden. The difference is crucial; the statement is typical of the way nations work as including and excluding concepts. It is a sort of criticism that implies that the problem with "Sweden" is that "we" play by, and respect the rules, while many other nations do not. This constructs, or reconstructs, an image of national problems as deriving from strengths. To be just and fair are not usually regarded as shortcomings, they can only become a problem in relation to the less noble actions of others. But the statement also helps reinterpret the time Fuglesang spent waiting to get into space. Unlike other nation's astronauts, Swedish ones, because of their national pedigree, know how to stand in line.

Fuglesang's achievements therefore are to be seen as authentic and genuine, and as resulting from hard work and determination, untainted by politics and power games. The Minister of Education's comment about the particle physicist turned hero is typical of the official attitude towards Fuglesang: he is a powerful mix of hero, idol and scientist, the perfect symbol for a knowledge-based nation intent on promoting public interest in science and technology and recruitment to educational programmes in these fields.

That it took fourteen years for Fuglesang to get into space is transformed from the basis for jokes and satire into a marker of the man's resolve. One of Fuglesang's books (2007) bears the title Thirteen Days in Space After Fourteen Years on Earth, the title plays on the popular image of Fuglesang's long struggle to gain a place on a space mission. His identity as an also-ran astronaut is, however, rewritten in the book in terms of a quest of stubborn determination where Fuglesang showed great perseverance never doubting he would one day be awarded the opportunity he so justly deserved. In a radio show, broadcast during the summer of 2007, Fuglesang reflects on his public image as the astronaut who was held back before being eventually granted a space mission. He claims that he never worried that he would never make it into space, and that he does not see fourteen years as an exceptionally long time spent preparing for such a major undertaking. Fuglesang takes up the theme of a goal-oriented achiever at the end of his "space diary":

To set a goal for oneself and then perform all that is needed to finally reach it is always gratifying. And the harder the goal is to reach, the more obstacles one has to 
pass on the way, the better the feeling afterwards. I have accomplished the biggest goal of my life so far. There were more obstacles on the way than I thought there would be on the day I was chosen as astronaut. I hope, and believe, that my space journey has given others the joy I felt myself. That my positive experience has rubbed off on others. (Fuglesang 2007: 333)

Hard work is seen as rewarding, and as a source of personal pleasure and pride in itself. Fuglesang accepts that to accomplish truly great things delayed gratification must be endured. Only then, can your achievements not only be a joy to yourself, but also to others. On December $15^{\text {th }} 2006$, Swedish television broadcast a live interview with Fuglesang and his colleague Thomas Ritter from on-board the International Space Station (TV4 2006). Before the interview a panel talked about Fuglesang's career, comparing him to other popular heroes like footballers and pop stars. The presenter marvelled at someone who is neither an athlete nor a pop singer, but whose fame has been won through hard graft, "this is a guy who has studied, he has done his homework...". The government minister in the studio, Maud Olofsson, added that it is his persistence that makes his achievement so special; Fuglesang has worked hard from his school years, getting a $\mathrm{PhD}$, and then single-mindedly dedicating himself to making it into space. She also commented that she hoped Fuglesang would serve as an example to others. This frame was then reinforced during the interview when a nine-year-old boy asked Fuglesang if he thought all the years of waiting had been worthwhile now that he was finally in space. Fuglesang replied that they had been very much worthwhile, but that he had not just waited, he had been working with the space program and that, in itself, had been a highly rewarding experience. Olofsson also wanted Fuglesang to promise to be a good ambassador for "all the kids who want to study science, we need many more like you who study and set grand goals for themselves.” (TV4 2006).

All these descriptions, comments and carefully planned questions underline the same basic theme; the Swedish member of the space program should be seen as a qualified, hard working and honest fellow. That it took so long before he made it into space should not be considered strange or as a sign of weakness, but as a sign of stubborn tenacity. Fuglesang did not buy his ticket into space; he earned it through selfless dedication to the continuing development of space exploration making him both a credit to science and the Swedish nation alike.

\section{How the First Swede in Space Envisions the Future.}

So far, the main aim of this text has been to analyse how Fuglesang came to be positioned as an ideal figure for re-asserting the autonomous authority of science in Swedish society. But the question of how the construction of Fuglesang as a popular science hero connects with attempts to enhance public confidence and faith in science and technology more generally remains to be addressed. In this 
last section, Fuglesang's envisioning of the future is scrutinised in order to discuss how his status as public hero allows him to remind the lay public of the benefits of science. In his more generally expressed hopes and fears for scientific, technological and social development, a sense of what is at stake in the practises of popularisation becomes clearer.

The popular science presented here revolves around one person, and science and technology are not explicitly dealt with as facts and artefacts. Rather than explaining and translating scientific details, the popular texts mentioned here are more accurately interpreted as arguments for science in general, and for the project of space exploration in particular. Thus, popular science in this context is about winning public support and license leading to the further enlargement of the scale and scope of autonomous scientific and engineering actions in society. This is partly done by popularisations of different details, but on the whole the idea is to re-assert faith in progress and place the future on a new scientific and technological frontier once more.

The message that Fuglesang delivers is that renewed public faith in science and technology will reward both those individuals and those societies who are willing and able to subject themselves to the rigours of science and engineering cultures. Thus, the science hero brings to life a vision of scientific and technical ingenuity as once again forces capable of solving the problems of our time:

Fresh water and easily accessible oil, two fundamental resources in the world today, risk being in short supply. We will have to work hard on Earth to share them, until new technology solves the problem forever. In the long run it's a temporary problem we're facing. But those of us who live now, and our children, want to pass it over as smoothly as possible. (Sveriges Radio 2007)

Science and technology will not only solve contemporary problems, they will also, as in the past, continue to open up new frontiers for the future. The science and technology of the space programme can even end up delivering our salvation, as is evident in this lengthy quote:

I picture to myself how mankind slowly but surely will expand its domain. First to the moon and Mars, then to other planets in our solar system and in time to distant stars and their planets. I envision how we shall land on Mars in twenty-five years, how self-sustaining colonies will be established there in a hundred years, how we shall travel the entire solar system in yet another couple of hundred years and finally build large space cities and travel to other stars. Since I don't have any science fiction-dreams of hyperspace or such, I count on these star voyages taking several thousand years. Most people get dumbfounded when one speaks of such time spans, but if we look back it is not that long. [...] Man has existed as Homo sapiens for a few hundred thousand years. Most things indicate that we originated in Africa and then during several thousands years wandered out across the Earth. Africa was our first cradle, Earth is our second and the solar system will be our third. But there is no reason to remain in any of them. Compared to life's total age on Earth, about three billion years, ten thousand years for a star voyage is but a moment. (Fuglesang \& Tell 2007: 246) 
The articulation of goals as grandiose as this is here made more likely by a combination of using two types of time frames, a more comprehensible one for the short term achievements to which I will return, and a far more abstract one for the establishment of human colonies in space. This second time scale is made more credible by reference not to the space programme, or other concrete endeavours, but to evolutionary time. Our travel through the galaxies should not be compared solely to the limited lives of human beings, but rather to the evolution of humankind itself. By alluding to evolutionary processes this progress is not only made more likely but also framed as a "natural" development. Space is our natural future home, or our "third cradle". There is no room in this account for an alternative trajectory for humankind, and there is a strong conviction that we must press on reaching for the stars, all that is required is renewed faith and belief, those precious resources that scientists and engineers are so often unfairly deprived of.

The smaller time scale is more modest, but it still outlines what needs to be done in order to make the grander one realisable. Fuglesang's visions of the future are full of qualifiers about political will and funding. So they are not only arguments for space exploration as a detached project, as he acknowledges the need for public support. Still he remains optimistic, for example, writing enthusiastically about future travels to Mars in the preface of a recent book by Ella Carlsson (2007) that tells of her participation in simulation work in preparation for a Mars landing. Projects such as these are important in the work of science communication as they supply narrative structure. Fuglesang's mission to the International Space Station is seen as one step in a much larger saga, one that started with Sputnik and will end with mankind colonising distant planets. This is how scientific and technological progress is made tangible and real. The narrative of a history, present and future that creates a whole makes every project a step towards something far greater.

In this light Fuglesang's commitment to combining his space mission with a public mission is more understandable, it is not hard to imagine that this is another part of the astronaut's duty towards the continuation of space exploration. The grand narrative of space colonisation supplies the space endeavour, with a definite sense of direction. Establishing and building a space station in orbit around Earth is just the first step in a far grander scheme of things. A development in which there is ample room and opportunity for a new generation of Swedish scientists and engineers to follow the example of the particle physics hero.

At the same time, this development is by no means given. The threat of public indifference might very well undermine the whole project. As science and technology continue to show the way into the future, there remain no guarantees that Swedish society at large will follow. The gap between science and the public may grow dauntingly large if the latter choose to wallow in ignorance rather than adopt the path to knowledge. The gap between science and the public is ultimately not 
the problem, so much as a failure on the part of the public to recognize its existence. As Fuglesang expresses it:

\begin{abstract}
What's worrying is when people confuse astronaut, astronomer and astrologer. The astronomer is someone who carries out research about stars and space and is close to me. But an astrologer is a person who claims that she or he can tell peoples' future based on where the planets are in the sky. Complete nonsense! I have few abominations but, pseudo-science in all its forms is one of them. It shocks me when charlatans and self-appointed fortune-tellers of different kinds deceive innocent and often vulnerable people. This holds for everything from horoscopes to a large part of socalled alternative medicine, for example homeopathy and cure by touch. (Sveriges Radio 2007)
\end{abstract}

That people confuse astronomers and astrologers tells of a dangerous form of ignorance that may be exploited. Science and pseudo-science are portrayed as unambiguous categories, the latter consisting of charlatans and swindlers, the former of unequivocally trustworthy scientists. That people read horoscopes, consult healers and partake in "pseudo-scientific" activities should not be seen as due to choice or preference, it is a sign of human weakness and vulnerability. The boundary work performed here is one that clearly sets science apart from other knowledge-producing activities, and equates true knowledge exclusively with science. The answer to the threat of ignorance and a lack of appreciation for science is framed as a request that the public pay heed to scientists in order not to be fooled. A lack of appreciation and interest for science is thus constituted as a social and political problem. Science communication is a way of protecting the public from false gods, regardless of the public's ability to understand the details of science, they must not lose faith in the vision of a science-based society. So in the end the gap between a knowledgeable science and an ignorant public is reestablished and the cultural leadership of science is reassured as the way towards an enlightened future society.

\title{
Conclusion
}

In summary, by studying the positioning of Fuglesang as a symbol for a divide between science and society which he personally has been able to literally rise above, has enabled us to address the reaffirmation of the cultural boundaries of science (cf. Gieryn 1983) in Swedish society. Once again, science is placed in a separate sphere, at once remote and yet crucial for the future development of the nation as a whole. A perceived lack of public support for autonomous science in society continually generates the need for appropriate mediators capable of bridging the science/society divide. In the aftermath of his belated launch into space, Fuglesang has been assigned a complementary earthbound mission as he has been launched into the breach of Swedish science and society relations. Simultaneously, rendering the gap between Swedish science and society more pronounced, 
while amply filling it with his heroism, Fuglesang has served to accentuate a particular division of cultural authority in society once more.

I would like to thank Mark Elam and the two anonymous referees of Culture Unbound for their helpful, constructive and supportive comments on earlier versions of this paper.

Andreas Gunnarsson is a PhD Student at the Section for Science and Technology Studies at Gothenburg University. He has previously published in Swedish on popular representations of genetics in film and fiction. His research interests centre on the popular as a site for public communication of science and technology.

\section{Notes}

1 A number of studies and articles in the field of Public Understanding of Science has been concerned with both describing and debunking this idea, sometimes referred to as "the dominant view of popularisation” e.g. Hilgartner (1990), or "the canonical account” e.g. Bucchi (1996), Grundmann \& Cavaillé (2000), or, as I do here, ”the deficit model” e.g. Miller (2001), Locke (2002) and Sturgis \& Allum (2004).

2 Many surveys and studies have been published in recent years that highlight either the decline of interest in science and science education or compare levels of interest in different countries, e.g. EU (2005), Sjøberg \& Schreiner (2005), see also studies from the Trends in International Mathematics and Science Study (TIMSS) and the OECD Programme for International Student Assessment (PISA). For a review of studies concerning students declining interests in science and scientific education see Osborne et al. (2003). For a typical view of what is wrong in the science-public relation and the dangers that entails see Dunbar (1995).

3 The work of analytically retrieving the situated traits of astronauts as scientific witnesses, and of the ones who have failed to qualify as modest witnesses in the space endeavour, is still ongoing (cf. Penley 1997; Wajcman 2000; Weitekamp 2004).

\section{References}

Aftonbladet (2007): "Himlar en sån superstjärna - Tusentals fans hyllade Christer Fuglesang”, January $27^{\text {th }}$.

Arendt, Hannah (1958): The Human Condition, Chicago: University of Chicago Press.

Bensaude-Vincent, Bernadette (2001): ”A Genealogy of the Increasing Gap Between Science and the Public", Public Understanding of Science, 10:1, 99-113.

Billig,Michael (1995): Banal Nationalism, London, Thousand Oaks, New Delhi: SAGE Publications.

Bryld, Mette and Nina Lykke (2000): Cosmodolphins: Feminist Studies of Technology, Animals and the Sacred, London: Zed. 
Bucchi, Massimiano (1996): "When Scientists Turn to the Public: Alternative Routes in Science Communication", Public Understanding of Science, 5:4, 375-394.

Carlsson, Ella (2007): Framåt Mars!, Stockholm: Farenheit.

Clynes, Manfred E. and Nathan S. Kline (1960/1995): "Cyborgs and Space”, Gray, Chris Hables (ed.): The Cyborg Handbook, New York and London: Routledge.

Cosgrove, Denis E. (2001): Apollo's Eye: A Cartographic Genealogy of the Earth in the Western Imagination, Baltimore: John Hopkins University Press.

Dagens Nyheter (1992): "Fuglesang vår man i rymden”, May $16^{\text {th }}$.

Dunbar, Robin (1995): The Trouble With Science, London: Faber and Faber.

EU (2005): Europeans, Science and Technology, Special Eurobarometer 224, Brussels: European Commission.

Expressen (1995): "Förste svensken i rymden”, March $17^{\text {th }}$.

Expressen (2003): ”Intervju. Christer Fuglesang. 'Om 20 år landar vi på Mars’”, March 30

Felt, Ulrike (2000): ”Why Should the Public 'Understand' Science? A Historical Perspective on Aspects of the Public Understanding of Science”, Dierkes, Meinolf and Claudia von Grote (eds.): Between Understanding and Trust. The Public, Science and Technology, Amsterdam: Harwood Academic Publishers.

Fuglesang, Christer and Johan Tell (2007): Människan i rymden: från Sputnik till Mars, Stockholm: Bokförlaget Max Ström.

(2007): 13 dygn i rymden efter 14 år på jorden: Dagbok från rymden av Christer Fuglesang, Stockholm: Albert Bonniers Förlag.

Gerovitch, Slava (2007): ”'New Soviet Man’ Inside Machine: Human Engineering, Spacecraft Design, and the Construction of Communism”, OSIRIS, 22, 135-157.

Gieryn, Thomas F. (1983): "Boundary-Work and the Demarcation of Science from Non-Science: Strain and Interests in Professional Ideologies of Scientists”, American Sociological Review, 48:6, 781-795.

Grundmann, Reiner and Jean-Pierre Cavaillé (2000): "Simplicity in Science and its Publics", Scence as Culture, 9:3, 353-389.

Hallands Nyheter / TT (2006): ”Fuglesang kritiserar Sverige”, November $21^{\text {st }}$.

Haraway, Donna J (1991): Simians, Cyborgs, and Women: the Reinvention of Nature, New York and London: Routledge.

— (1997): Modest_Witness@Second_Millennium.FemaleMan@_Meets_OncoMouse ${ }^{\mathrm{TM}}$ : Feminism and Technoscience, New York \& London: Routledge.

Hilgartner, Stephen (1990): "The Dominant View of Popularisation: Conceptual Problems, Political Uses”, Social Studies of Science: 20:3, 519-539.

Launius, Roger D (2005): "Heroes in a Vacuum: the Apollo Astronaut as Cultural Icon”, 43rd AIAA Aerospace Sciences Meeting and Exhibit, AIAA-2005-702.

Locke, Simon (2002): ”The Public Understanding of Science - a Rhetorical Invention”, Science, Technology \& Human Values, 27:1, 87-111.

Miller, Steve (2001): "Public Understanding of Science at the Crossroads”, Public Understanding of Science, 10:1, 115-120.

Myers, Greg (2003): ”Discourse Studies of Scientific Popularization: Questioning the Boundares”, Discourse Studies, 5:2, 265-279.

Nye, David E (1994): American Technological Sublime, Cambridge: MIT Press.

Osborne, Jonathan, Shirley Simon and Sue Collins (2003): "Attitudes Towards Science: A Review of the Literature and its Implications”, International Journal of Science Education, 25:9, 10491079.

Penley, Constance (1997): NASA/TREK: Popular Science and Sex in America, London \& New York: Verso.

Peters, John Durham (2001): ”Witnessing”, Media, Culture \& Society, 23:6, 707-723.

Romanyshyn, Robert D (1992): Technology as Symptom and Dream, London \& New York: Routledge.

Shapin, Steven and Simon Schaffer (1985): Leviathan and the Air-pump: Hobbes, Boyle and the Experimental Life, Princeton: Princeton University Press. 
Shaw, Debra Benita (2004): "Bodies Out of This World: The Space Suit as Cultural Icon”, Science as Culture, 13:1, 123-144.

Sjøberg, Svein and Camilla Schreiner (2006): "How Do Learners in Different Cultures Relate to Science and Technology? Results and Perspectives from the Project ROSE (the Relevance of Science Education)", APFSLT: Asia-Pacific Forum on Science Learning and Teaching, 7(1).

Sturgis, Patrick and Nick Allum (2004): "Science in Society: Re-evaluating the Deficit Model of Public Attitudes", Public Understanding of Science, 13:1, 55-74.

Svenska Dagbladet (2002): "Klartecken för förste svensken i rymden”, February $28^{\text {th }}$.

Sveriges Radio (2007): "Sommar i P1: Christer Fuglesang", August $12^{\text {th }}$.

SVT (1996): Percy tårar.

TV4 (2006), "Intervju med Christer Fuglesang från rymden”, December $15^{\text {th }}$.

Wajcman, Judy (2000): "Reflections on Gender and Technology Studies: In what State is the Art?", Social Studies of Science, 30:3, 447-464.

Weitekamp, Margaret A. (2004): Right Stuff, Wrong Sex: America's First Women in Space Program, Baltimore: Johns Hopkins University Press.

Wolfe, Tom (1979): The Right Stuff, New York: Bantam Books.

Wynne, Brian (1995): "Public Understanding of Science”, Jasanoff, Sheila et al. (eds.) Handbook of Science and Technology Studies, Thousand Oaks: SAGE.

Östersundsposten / TT Spektra (2006): "449 människor (och ett par hundar) har varit i rymden", December 7th.

\section{Internet-sources}

The OECD Programme for International Student Assessment (PISA): http://www.pisa.oecd.org (2007 December $20^{\text {th }}$ ).

The Trends in International Mathematics and Science Study (TIMSS): http://timss.bc.edu (2007 December $\left.20^{\text {th }}\right)$. 